\title{
Article
}

\section{A Molecular Genetics Laboratory Course Applying Bioinformatics and Cell Biology in the Context of Original Research}

\author{
Cynthia J. Brame, ${ }^{*}$ Wendy M. Pruitt, ${ }^{\dagger}$ and Lucy C. Robinson ${ }^{\ddagger}$
}

${ }^{*}$ Department of Biology, Centenary College of Louisiana, Shreveport, LA 71105; and ${ }^{\dagger}$ Departments of Molecular and Cellular Physiology and $\ddagger$ Biochemistry and Molecular Biology, Louisiana State University Health Sciences Center, Shreveport, LA 71105

Submitted July 7, 2008; Revised August 31, 2008; Accepted September 18, 2008

Monitoring Editor: Robin Wright

\begin{abstract}
Research-based laboratory courses have been shown to stimulate student interest in science and to improve scientific skills. We describe here a project developed for a semester-long researchbased laboratory course that accompanies a genetics lecture course. The project was designed to allow students to become familiar with the use of bioinformatics tools and molecular biology and genetic approaches while carrying out original research. Students were required to present their hypotheses, experiments, and results in a comprehensive lab report. The lab project concerned the yeast casein kinase 1 (CK1) protein kinase Yck2. CK1 protein kinases are present in all organisms and are well conserved in primary structure. These enzymes display sequence features that differ from other protein kinase subfamilies. Students identified such sequences within the CK1 subfamily, chose a sequence to analyze, used available structural data to determine possible functions for their sequences, and designed mutations within the sequences. After generating the mutant alleles, these were expressed in yeast and tested for function by using two growth assays. The student response to the project was positive, both in terms of knowledge and skills increases and interest in research, and several students are continuing the analysis of mutant alleles as summer projects.
\end{abstract}

\section{INTRODUCTION}

Various organizations examining science education have concluded that an inquiry-based approach to learning is essential to understanding science as a process (Howard Hughes Medical Institute, 1996; Council on Undergraduate Research, 1997; National Research Council [NRC], 2003). As a consequence, many laboratory courses have shifted away from "cookbook" exercises toward an inquiry-based model, allowing students to feel the self-investment and excitement that comes with discovery of new knowledge (Stukus and Lennox, 2001; Eberhardt et al., 2003; Mitchell and Graziano, 2006). Multiweek, inquiry- or research-based projects have been demonstrated to be an effective means of stimulating student interest and enhancing skills in experimental design and interpretation (Myers and Burgess, 2003; Gammie and

DOI: $10.1187 /$ cbe. $08-07-0036$

Address correspondence to: Cynthia J. Brame (cbrame@centenary.edu).
Erdeniz, 2004; Howard and Miskowski, 2005; Mitchell and Graziano, 2006; Goyette and DeLuca, 2007). In addition, there is an increasing need to incorporate the use of bioinformatics tools into such projects and into undergraduate biology classes in general (NRC, 2003).

Here, we report a semester-long research project that requires students to use bioinformatics tools to design and interpret a molecular biology-based experiment investigating structural determinants of protein kinase activity. Our goals for the course were to allow students to experience the excitement and challenges of original research while increasing their ability to understand and use the tools of the modern molecular biologist. Our specific learning objectives were as follows:

1. Students will gain understanding of genetics concepts and molecular biology techniques through using them in the context of a multi-step research project;

2. Students will learn to use protein and nucleotide data- 
bases and bioinformatics tools to investigate conserved protein features; and

3. Students will demonstrate increased ability to analyze and communicate the results of a multi-step project.

The results from a knowledge survey administered at the beginning and end of the semester indicate that learning objectives 1 and 2 were met, whereas assessment of lab reports over the course of the semester indicated that objective 3 was met. In addition, student perceptions of the project indicate that they felt the process facilitated their learning.

\section{Background for the Research Project}

This project focuses on casein kinase 1 (CK1) protein kinases, using the yeast enzyme Yck2 as a model CK1. The CK1 subfamily of protein kinases comprises a diverse group of kinases found in all eukaryotic cells. CK1 protein kinases from multicellular organisms regulate processes, including synaptic transmission (Faundez and Kelly, 2000), receptor signaling (Tobin et al., 1997), circadian rhythm (Lee et al., 2001), DNA repair (Knippschild et al., 1997), nuclear import (Vielhaber et al., 2000), and cell division (Brockman et al., 1992). CK1 activities also have been implicated with roles in neurodegenerative diseases, including Alzheimer's disease, and could be involved in a variety of cancers (Schwab et al., 2000; Rubinfeld et al., 2001). CK1 enzymes phosphorylate Ser or Thr residues $\mathrm{C}$-terminal to acidic residues. The classical site for CK1 is Asp/Glu-X-X-Ser/Thr (Tuazon and Traugh, 1991), but it has been demonstrated that $P \sim S e r / P \sim T h r-X-$ $\mathrm{X}$-Ser/Thr provides high-affinity CK1 recognition for the downstream Ser/Thr residue (Flotow and Roach, 1989).

Yck2 together with Yck1 forms a pair of essential and redundant kinases in the budding yeast Saccharomyces cerevisiae (Robinson et al., 1993; Vancura et al., 1993). The Yck proteins are essential for cell division and viability, and in addition to other functions, they seem to be involved in membrane protein turnover, bud site selection, polarization of the actin cytoskeleton, and function of the septin ring that is essential for cytokinesis in yeast (Robinson et al., 1993; Panek et al., 1997; Robinson et al., 1999; Marchal et al., 2002). In accord with functions at the plasma membrane, Yck2 was found to be a peripheral membrane protein of approximately $62 \mathrm{kDa}$ (Vancura et al., 1993). Yck2 is anchored to the membrane via palmitoylation of its two terminal cysteine residues (Roth et al., 2002; Babu et al., 2004). Targeting to the plasma membrane (as opposed to internal membranes) requires the $48 \mathrm{C}$-terminal residues that seem to be required solely for palmitoylation (Babu et al., 2004).

We used a previously generated green fluorescent protein (GFP)-tagged YCK2 clone and two yeast strains to assess the function of the student-generated mutant alleles: a $y c k^{t s}$ (yck1::ura3 yck2-2ts) yeast strain in which YCK1 is deleted and the yck2-2 $2^{\text {ts }}$ gene product functions at $24^{\circ} \mathrm{C}$ but has little activity at $37^{\circ} \mathrm{C}$ (Robinson et al., 1993), and a ycks strain (yck1 $::$ KanMX, yck2 $\Delta::$ NatMX) in which both YCK1 and $Y C K 2$ have been deleted and Yck activity is provided by a plasmid-borne YCK2 allele ( $p R S 316$ : YCK2; URA3). These tools, available on request, allowed easy manipulation of the YCK2 gene as well as two simple functionality assays. All other molecular biology supplies we used are commercially available, and all bioinformatics tools we used are freely available on the World Wide Web.

\section{Course Context}

This project was implemented in Biology 313 (BIOL 313, Genetics) at Centenary College of Louisiana. BIOL 313 is a survey genetics course that is required for all biology majors and is taken by most biochemistry and biophysics majors. The course enrolls between 40 and 50 students each spring, and consists of $3 \mathrm{~h}$ of lecture and $3 \mathrm{~h}$ of lab each week for 14 wk. There are typically three lab sections, limited to a maximum of 18 students per section. Approximately one-third of the students taking the course are sophomores, approximately $40 \%$ are juniors, and approximately one-fourth are seniors. All students taking the course have completed two semesters of general chemistry and a one-semester introductory cell biology course; many are concurrently enrolled in the second semester of organic chemistry. Because the lecture section of the course covers a broad range of topics, ranging from classical genetics to molecular genetics, the lab project proceeds independently of the lecture section of the course. The instructors refer to the lab project whenever relevant topics (e.g., cloning) are covered in lecture, providing students with concrete examples illustrating various lecture topics.

\section{METHODS}

\section{Preparation}

Each week, students received a document describing the purpose of the week's activity, the techniques used for the activity, and any other background information needed. Students were expected to read these documents before attending lab. These documents are available as Supplementary Material 1.

\section{Identifying Conserved Sequences in CK1 Enzymes}

The instructor reviewed conserved features of protein kinases with each lab section based on three reviews, all of which were made available for students' reference (Hanks et al., 1988; Hanks and Hunter, 1995; Hanks, 2003). After reviewing the concepts of conserved sequences and protein families, students identified conserved amino acid sequences in CK1 enzymes of at least six amino acids. Specifically, students obtained sequences of CK1 enzymes from the National Center for Biotechnology Information (NCBI) protein database (www.ncbi.nlm.nih.gov/sites/entrez), choosing at least one $\alpha$, one $\beta$, and one $\gamma$ CK1 as well as the yeast enzymes Yck1 and Yck2. Students aligned these protein sequences using ClustalW (align.genome.jp; Higgins and Sharp, 1988) and identified conserved sequences. The students consulted a table displaying conserved kinase sequences to determine whether these conserved sequences were specific to CK1 enzymes (Hanks and Hunter, 1988).

To put the CK1-specific conserved sequences in context of CK1 structure, the students used Cn3D and the NCBI Structure database to highlight the conserved sequences in a model CK1 (CK1 from Schizosaccharomyces pombe complexed with $\mathrm{Mg}^{2+}$-ATP; www.ncbi. nlm.nih.gov/structure). After identifying the ATP-binding lobe, the substrate-binding lobe, and each of the conserved sequences, the students formed hypotheses about the function of each conserved sequence. Each lab section then chose a single conserved sequence on which to focus, and each lab group (composed of two to three students) determined the mutation within that sequence that they wished to make. The instructor encouraged the lab groups to work together in designing these mutations, suggesting that the muta- 
tions could be more informative if different groups made complementary mutations. For example, within a lab section focusing in part on a highly conserved proline, one lab group deleted the proline, one made a conservative mutation, and one made a nonconservative mutation.

\section{Designing Primers}

Students obtained the YCK2 open reading frame (ORF) sequence from the Saccharomyces Genome Database (www.yeastgenome.org) and used this to identify the nucleotides corresponding to their conserved amino acid sequence. Using rules for primer design provided with the Stratagene QuikChange kit, students then designed primers to introduce their mutation. Specifically, students attempted to design primers that were between 25 and 45 nucleotides, with a melting temperature of $\geq 78^{\circ} \mathrm{C}$, a minimum GC content of $40 \%$, and terminated in one or more $\mathrm{C}$ or $\mathrm{G}$ bases. The instructor examined each pair of primers and suggested changes when appropriate. When it was not possible to design primers that adhered to all the desired parameters, the instructor often designed a second primer set to increase the probability of a successful mutagenesis reaction. All primers were synthesized by Integrated DNA Technologies (Coralville, IA) at the 100-nmol level and were used without purification.

\section{Site-directed Mutagenesis}

Mutagenesis reactions were performed using the QuikChange kit according to manufacturer's instructions (Stratagene, Cedar Creek, TX). Unless otherwise noted, all reagents were provided with the QuikChange kit. Briefly, each student group performed two mutagenesis reactions, using 5 and $10 \mathrm{ng}$ of pLR10 (pUC18:GFP-YCK2; Robinson et al., 1999) as template. The GFP fusion in this plasmid has native YCK2 flanking sequences upstream and downstream, including the native YCK2 promoter (Robinson et al., 1999). The forward and reverse primers ( $125 \mathrm{ng}$ ) designed by the students were used in the reactions; when the instructors identified potential shortcomings of the students' primer design, students performed duplicate reactions with a primer set designed by the instructors. The reactions also contained reaction buffer, dNTP mix, PfuTurbo DNA polymerase, and water to a final volume of $50 \mu \mathrm{l}$. Reactions were carried out in an Eppendorf thermal cycler as follows: 1 cycle: $95^{\circ} \mathrm{C} 30 \mathrm{~s} ; 18$ cycles: $95^{\circ} \mathrm{C} 30 \mathrm{~s}, 55^{\circ} \mathrm{C} 1 \mathrm{~min}, 68^{\circ} \mathrm{C} 5 \mathrm{~min}$. Template DNA was then digested by incubation with DpnI for $1 \mathrm{~h}$ at $37^{\circ} \mathrm{C}$. XL-1 Blue supercompetent cells were thawed on ice and separated into $50-\mu \mathrm{l}$ aliquots in prechilled 14-ml BD Falcon polypropylene round-bottomed tubes (Thermo Fisher Scientific, Waltham, MA). Supercompetent cells were incubated with $1 \mu$ l of each DpnI-treated mutagenesis reaction for $30 \mathrm{~min}$. The cells were heat-shocked at $42^{\circ} \mathrm{C}$ for $45 \mathrm{~s}$ and then incubated on ice for $2 \mathrm{~min}$. Preheated SOC broth was added and cells were incubated for $1 \mathrm{~h}$ at $37^{\circ} \mathrm{C}$ with shaking. Half the volume of each transformation reaction was then plated on Luria-Bertani (LB)-ampicillin medium and incubated at $37^{\circ} \mathrm{C}$ overnight. Each student group picked three colonies with sterile toothpicks and grew these in LB containing $100 \mu \mathrm{g} / \mathrm{ml}$ ampicillin overnight at $37^{\circ} \mathrm{C}$ with shaking.

\section{Plasmid Preparation}

Plasmid minipreps were performed using the Zyppy Prep I miniprep kit (Zymo Research, Orange, CA) according to manufacturer's instructions. Briefly, cells from $3 \mathrm{ml}$ of liquid culture were pelleted by brief centrifugation in a $1.5-\mathrm{ml}$ microfuge tube at full speed. The supernatant was discarded, and the cell pellet was resuspended in buffer P1 and lysed by addition of buffer P2. Buffer P3 was added to precipitate cell debris. The tube was centrifuged for $3 \mathrm{~min}$ at full speed, and the supernatant was loaded into the Zymo-spin column, avoiding carrying over any cell debris. The Zymo-spin column and collection tube were centrifuged at full speed for $30 \mathrm{~s}$, allowing the liquid to flow through the column. The flow through in the collection tube was discarded and the resin was washed with wash buffer. The column was transferred to a sterile $1.5-\mathrm{ml}$ microfuge tube and DNA was eluted with $40 \mu \mathrm{l}$ of water.

\section{Analytical Digest of Mutagenized DNA before Sequencing}

Miniprep DNA was analyzed by restriction enzyme digest and gel electrophoresis. One microliter of each sample was incubated with $2 \mathrm{U}$ of BamHI and $2 \mathrm{U}$ of SalI in buffer D (all from Promega, Madison, WI) for $1 \mathrm{~h}$ at $37^{\circ} \mathrm{C}$. The digested samples were then combined with loading buffer (Sambrook et al., 1989), loaded in a $1 \%$ agarose gel containing $1 \mu \mathrm{g} / \mathrm{ml}$ ethidium bromide, and subjected to electrophoresis for approximately $1 \mathrm{~h}$ at $120 \mathrm{~V}$. Results were visualized with UV light.

\section{Sequencing}

Each student group chose three samples for sequence analysis. Approximately $1000 \mathrm{ng}$ of DNA to be sequenced and approximately 100 pmol of the appropriate sequencing primer were sent to Retrogen (San Diego, CA) for automated dideoxy sequencing. Due to the high fidelity of PfuTurbo and the cost of multiple sequencing reactions for each clone, only the region of interest was sequenced for each clone for the lab course. Mutations in the LLGPSLED region used the sequencing primer 5'-GGGCTGCACTATAAGATAG-3', mutations in the HIPYRE region were analyzed with the sequencing primer 5'-CTGTTGTACAAGTCG-3', and mutations in the EQSRRDD region were analyzed with the sequencing primer 5 '-GGAAGACCGGGTCAACC-3' (all from Integrated DNA Technologies). Students analyzed the results of the sequencing using the BLAST algorithm (Altschul et al., 1990). Specifically, they used BLAST to align the sequences obtained from Retrogen with YCK2 sequence. The alignment was used to verify that their mutant allele was identical to wild-type YCK2 except at the mutation site.

\section{Preparative Digest to Isolate GFP-mYCK2 Fragment}

Each student group chose one clone containing the desired mutation for further use and subjected it to a preparative digest to remove the GFP- $m Y C K 2$ fragment from the vector. Specifically, 2-3 $\mu \mathrm{g}$ of DNA was incubated for $2 \mathrm{~h}$ at $37^{\circ} \mathrm{C}$ in buffer $\mathrm{H}$ with $5 \mathrm{U}$ each XbaI and SacI (all from Promega) in a final volume of $25 \mu \mathrm{l}$. Samples were then mixed with loading buffer, loaded in a $1 \%$ agarose gel containing $1 \mu \mathrm{g} / \mathrm{ml}$ ethidium bromide, and electrophoresed as described above. Results were visualized with UV light, and the band corresponding to the GFP-mYCK2 fragment was excised with a scalpel and stored at $4^{\circ} \mathrm{C}$ for purification.

\section{GFP-mYCK2 Fragment Purification}

Purification of the GFP- $m Y C K 2$ fragments was performed using a Wizard SV DNA purification kit (Promega, Madison, WI) according to manufacturer's instructions. Briefly, the agarose gel slice was melted in membrane binding solution (MBS), by using $10 \mu \mathrm{l}$ of MBS for every $10 \mathrm{mg}$ of agarose, at $60^{\circ} \mathrm{C}$. The dissolved gel was loaded into an SV minicolumn and incubated for $1 \mathrm{~min}$ at room temperature. After the incubation, the minicolumn was centrifuged for 1 min at full speed. The liquid in the collection tube was discarded, and the column was washed twice with membrane wash solution. The SV minicolumn was transferred to a clean $1.5-\mathrm{ml}$ microfuge tube, and $50 \mu \mathrm{l}$ of water was added. The minicolumn was incubated at room temperature for $1 \mathrm{~min}$ and then centrifuged at full speed for 2 min to elute the purified GFP-mYCK2 fragment.

\section{Ligation}

To construct low copy plasmid containing GFP-mYCK2 under the control of the native YCK2 promoter, the purified GFP-mYCK2 fragment was ligated into pRS315 (CEN, LEU2; Sikorski and Hieter, 1989). Ligation was performed using a LigaFast kit (Promega) according to manufacturer's instructions. Students incubated $100 \mathrm{ng}$ of GFP-mYCK2 with $70 \mathrm{ng}$ of XbaI/SacI-digested pRS315 shuttle vector in a 16- $\mu$ l reaction with $3 \mathrm{U}$ of DNA ligase. Reactions were incubated for $10 \mathrm{~min}$ at room temperature and then used to transform $100 \mu \mathrm{l}$ of chemically competent $\mathrm{DH} 5 \alpha$ Escherichia coli cells. Frozen competent cells were thawed on ice, and $100 \mu$ l was incubated with the ligation mixture on ice for $30 \mathrm{~min}$. The cells were 
heat-shocked at $42^{\circ} \mathrm{C}$ for $3 \mathrm{~min}$ and then incubated on ice for $2 \mathrm{~min}$. The cells were then incubated with $0.5 \mathrm{ml}$ of preheated LB for $1 \mathrm{~h}$ at $37^{\circ} \mathrm{C}$ with shaking. Next, $250 \mu \mathrm{l}$ of each reaction was plated on LB-ampicillin plates and incubated at $37^{\circ} \mathrm{C}$ overnight. After development of colonies, colonies were inoculated into LB plus $0.1 \%$ ampicillin and incubated overnight at $37^{\circ} \mathrm{C}$ with shaking. Each student group grew four liquid cultures and purified plasmid DNA from each using the miniprep procedure described above.

\section{Analytical Digest of Shuttle Vector: GFP-mYCK2 Construct}

Miniprep results were analyzed by restriction digest and gel electrophoresis. One microliter of each sample was incubated in a total volume of $10 \mu \mathrm{l}$ with $2 \mathrm{U}$ of XbaI and $2 \mathrm{U}$ of SacI in buffer $\mathrm{H}$ (all from Promega) for $1 \mathrm{~h}$ at $37^{\circ} \mathrm{C}$. Reactions were then combined with loading buffer and electrophoresed as described above. Results were visualized with UV light.

\section{Preparation of Calf Thymus Carrier DNA}

Calf thymus DNA (Sigma-Aldrich, St. Louis, MO) was prepared as a $10 \mathrm{mg} / \mathrm{ml}$ solution in TE and sheared sequentially with 18-, 22and 26-gauge needles. The solution was then autoclaved for $15 \mathrm{~min}$ before incubating on ice for $10 \mathrm{~min}$. Aliquots were stored at $-20^{\circ} \mathrm{C}$. Each aliquot was boiled for $10 \mathrm{~min}$ and then placed on ice immediately before use.

\section{Preparation of Yeast Media and Plates}

Media were prepared as described previously (Sherman et al., 1986).

\section{Yeast Transformation and Culture}

Students used a modified version of the LiOAc transformation procedure of Gietz and Schiestl (1991). For each pair of student groups, $10 \mathrm{ml}$ YPD cultures were inoculated with $y c k^{t s}$ yeast

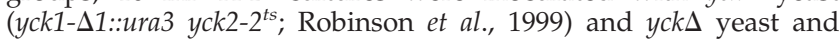
grown overnight at $24^{\circ} \mathrm{C}$ with shaking. Approximately $3 \mathrm{~h}$ before use, each culture was diluted to $100 \mathrm{ml}$ in YPD and grown at $24^{\circ} \mathrm{C}$ with shaking. Cells were then pelleted by low-speed centrifugation and the cell pellet was washed with sterile water and resuspended in lithium acetate in TE $(0.1 \mathrm{M} \mathrm{LiOAc/TE})$. One hundred microliter aliquots of the competent cells were added to prechilled microfuge tubes containing $75 \mu \mathrm{g}$ of calf thymus DNA and $2 \mu \mathrm{g}$ of pRS315: $G F P-m Y C K 2$. Each student group carried out a no DNA control (no plasmid), a positive control ( $2 \mu \mathrm{g}$ pRS315:GFP-YCK2), and a negative control ( $2 \mu \mathrm{g}$ pRS315). Then, $600 \mu \mathrm{l}$ of $40 \%$ polyethylene glycol/ $0.1 \mathrm{M}$ lithium acetate in TE was added, followed by gentle mixing by inversion. The tubes were then incubated at room temperature for $30 \mathrm{~min}$ on a rotating platform. Dimethylsulfoxide $(70 \mu \mathrm{l})$ was then added to each sample, and each sample was mixed by inversion and then heat shocked at $42^{\circ} \mathrm{C}$ for $6 \mathrm{~min}$. After rapid cooling for $2 \mathrm{~min}$ on ice, cells were pelleted at $3000 \mathrm{rpm}$ for $3 \mathrm{~min}$, the supernatant was discarded, and the pellet was resuspended in $1 \mathrm{ml}$ of -Leu medium. One tenth of each sample was then plated on a - Leu plate by using sterile 4-mm glass beads. The plates were allowed to develop colonies for several days at room temperature ( $y c k^{t s}$ cells) or $30^{\circ} \mathrm{C}$ (ycks cells). Four colonies from each reaction were patched to - Leu plates and grown overnight at $24^{\circ} \mathrm{C}\left(y c k^{t s}\right.$ cells) or at $30^{\circ} \mathrm{C}$ (ycks cells). Patches were then replica plated to two -Leu plates incubated at 24 and $37^{\circ} \mathrm{C}$ (yck cells) or to - Leu and

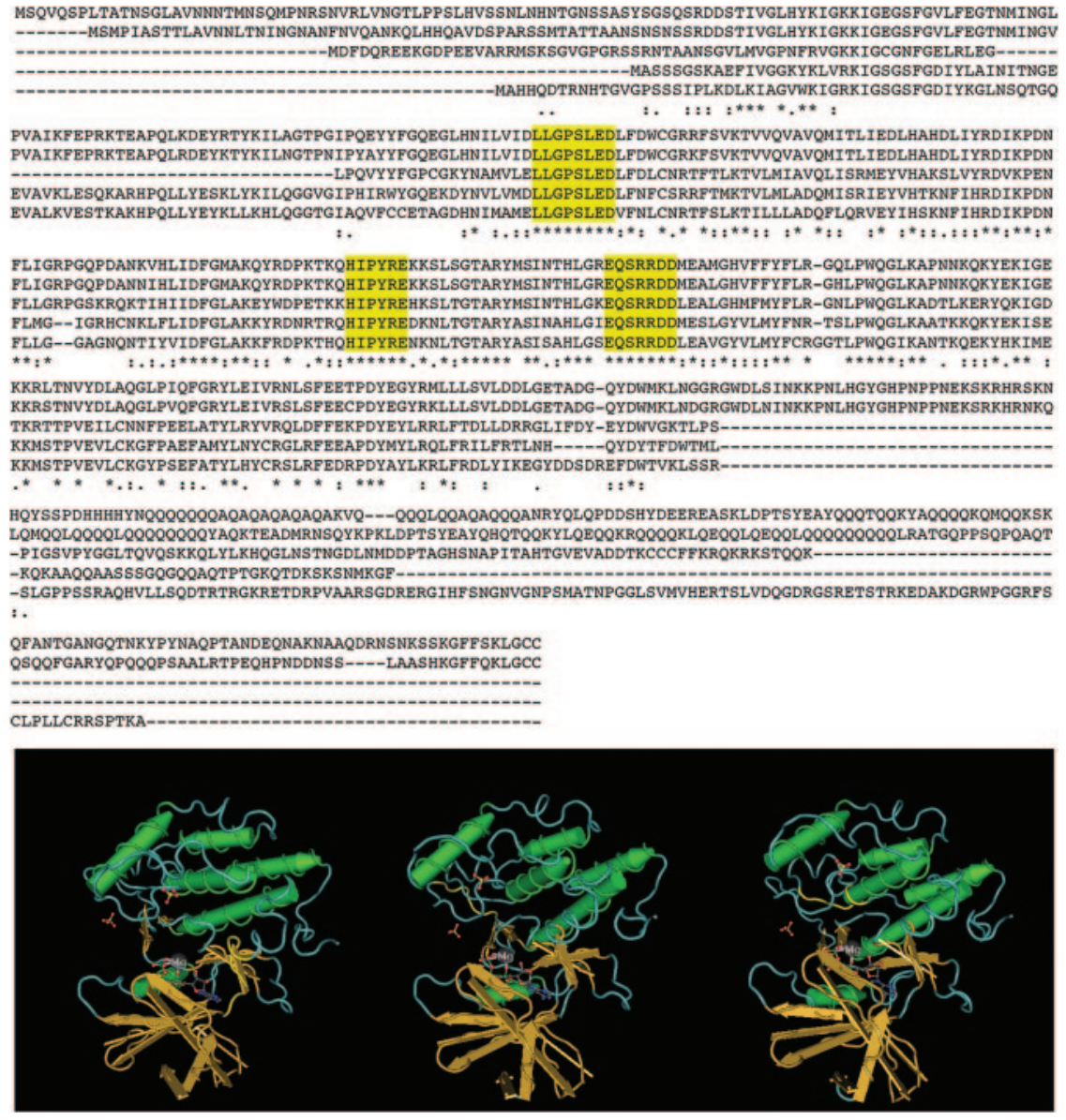

Figure 1. Conserved amino acids in CK1s. ClustalW alignment of amino acid sequences from five CK1 protein kinases (Yck2 from $S$. cerevisiae, Yck1 from S. cerevisiae, CK1 $\alpha$ from Xenopus laevis, CK1 $\beta$ from Toxoplasma gondii, and $\mathrm{CK} 1 \gamma$ from Xenopus tropicalis). The star designations beneath a text column indicate complete conservation of the amino acid. Highlighted in yellow are the conserved sequences LLGPSLED, HIPYRE, and EQSRRDD. (Left to right) Cn3D three-dimensional representations of CK1 from Schizosaccharomyces pombe bound to $\mathrm{Mg}^{2+}$-ATP. The conserved sequences identified above are highlighted below in yellow (left to right, LLGPSLED, HIPYRE, and EQSRRDD). 
5-fluoro-orotic acid (5-FOA) plates incubated at $30^{\circ} \mathrm{C}$ (yck $\Delta$ cells). Function was assessed by comparing growth in permissive and restrictive conditions.

\section{Visualization}

Yeast cells grown overnight on agar medium in restrictive conditions were scraped from patches, suspended in 2-5 $\mu$ l of water, placed under a coverslip, and examined by bright field and fluorescence microscopy.

\section{Assessment}

To determine whether educational goals 1 and 2 were achieved, student knowledge and skills were assessed with a pretest the first day that the lab met. The same test also was included on the final exam as a posttest. To compare responses to individual questions, student responses from each lab section were averaged. A twotailed paired $t$ test was performed to determine whether the learning gain for each question was significant. To compare individual student learning on the entire test, a two-tailed paired $t$ test was performed without regard to individual lab sections. The test is provided in Supplemental Material 2.

To determine whether educational goal 3 was achieved, student lab reports were assessed using a rubric (provided in Supplemental Material 2). Students wrote a lab report at midterm detailing their results for the first half of the project. They were then allowed to revise this lab report to replace their initial grade. Students also wrote a final lab report detailing the results for the second half of the project, but they were unable to revise this report. Scores on the first lab report were compared with the revision and to the second lab report; in both cases, the significance of the change was determined with a two-tailed paired $t$ test.

Students also completed an attitudes survey at the end of the course assessing their perceptions of the extent to which the lab activities facilitated their learning.

\section{RESULTS}

\section{Overview of Project}

Students worked in groups of two or three to identify conserved amino acid sequences in CK1 protein kinases, visualize their locations on a CK1 structure by using the Cn3D software (www.ncbi.nlm.nih.gov/Structure/CN3D/ cn3d.shtml), and form hypotheses about the function of each conserved sequence (Figure 1). Each lab section (composed of five to six student groups and as many as 18 students) then chose one conserved sequence with which to work and devised mutations to investigate the function of this sequence, with each student group focusing on a different mutation. Each student group designed primers to generate their mutation within Yck2, a CK1 from budding yeast (Table 1). The primers were used with the QuikChange kit (Stratagene) to perform site-directed mutagenesis (Figure 2). The students verified generation of their desired mutant allele by nucleotide sequence analysis of the mutated region. The mutant alleles were then cloned into a yeast/E. coli shuttle vector and used to transform two strains of yeast,

Table 1. Student-designed mutations and mutagenic primers

\begin{tabular}{|c|c|c|}
\hline Conserved sequence & Mutation & Mutagenic primer $\left(5^{\prime} \rightarrow 3^{\prime}\right.$; forward primer only) \\
\hline \multirow{7}{*}{${ }^{151}$ LLGPSLED } & & *ATATTGGTTATTGATTTATTCGATTGGTG \\
\hline & & *ATATTGGTTATTGATCCTTCTTTAGAAGAT \\
\hline & $\Delta \mathrm{P}$ & GATCTGCTTGGTTCTTTAGAAG \\
\hline & & *GATCTGCTTGGTTCTTTAGAAGATTTA \\
\hline & $\Delta$ PSLED & GGTTATTGATCTGCTTGGTTTATTCGATTGGTGTGG \\
\hline & & *GATCTGCTTGGTTGGTCTTTAGAAG \\
\hline & $\mathrm{P} \rightarrow \mathrm{E}$ & GATCTGCTTGGTGAGTCTTTAGAAG \\
\hline \multirow[t]{5}{*}{${ }^{233} \mathrm{HIPYRE}$} & $\Delta \mathrm{P}$ & ACTAAACAACATATTTACAGGGAAAAGAAA \\
\hline & & CTAAACAACATATTTACAGGGAAAAG \\
\hline & $\mathrm{P} \rightarrow \mathrm{V}$ & CTAAACAACATATTGTGTACAGGGAAAAG \\
\hline & $\mathrm{P} \rightarrow \mathrm{T}$ & CTAAACAACATATTACGTACAGGGAAAAG \\
\hline & DY & AACAACATATTCCGAGGGAAAAGAAATC \\
\hline \multirow{6}{*}{${ }^{258}$ EQSRRDD } & $\mathrm{S} \rightarrow \mathrm{T}$ & GGTAGAGAACAAACGAGAAGAGACGATATG \\
\hline & & *GGTAGAGAACAAACGAGAAGAGACGAT \\
\hline & $\mathrm{S} \rightarrow \mathrm{C}$ & CATTTGGGTAGAGAACAATGCAGAAGAGACGATATGGAAGCT \\
\hline & & *TGGGTAGAGAACAATGCAGAAGAGACGATATG \\
\hline & $\mathrm{DD} \rightarrow \mathrm{NN}$ & GAACAATCGAGAAGAAACAATATGGAAGCTATGG \\
\hline & RRDD $\rightarrow$ GGGG & AGAGAACAATCGGGAGGAGGCGGTATGGAAGCTAT \\
\hline
\end{tabular}

The numbering for the conserved sequences corresponds to Yck2 amino acid sequence. The forward primers for site-directed mutagenesis designed by students and by instructors $\left(^{*}\right)$ are shown. It was not possible to design primers for the ${ }^{151}$ LLGPSLED region that corresponded to all the desired parameters; thus, in most cases, the instructors provided a second set of primers to increase the probability of a successful mutagenesis reaction. 

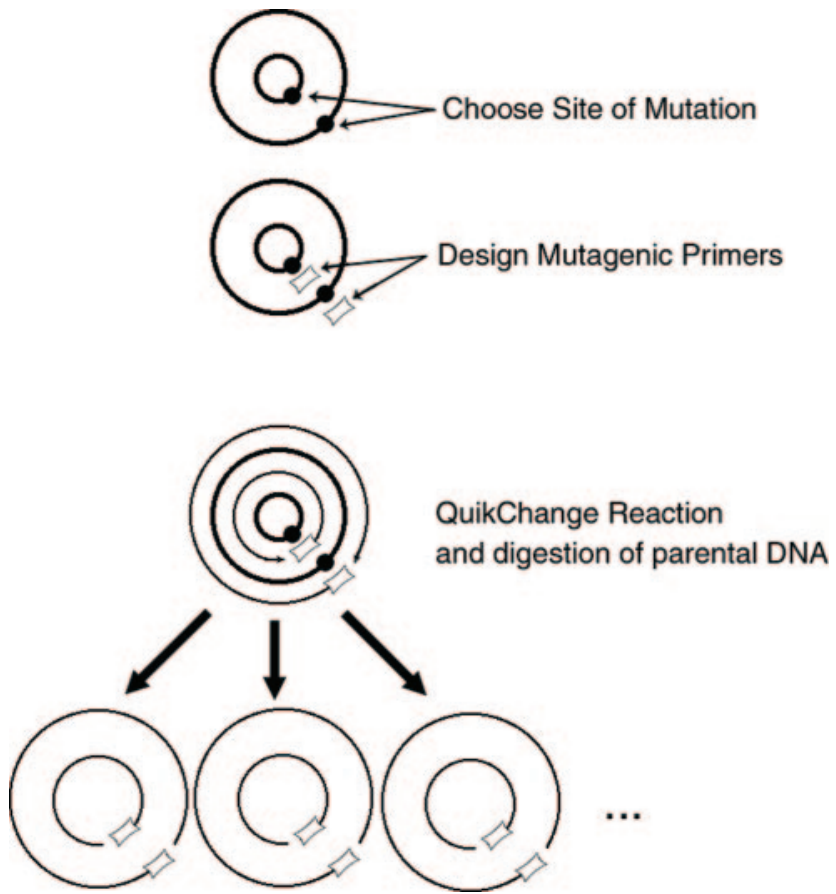

Figure 2. Site-directed mutagenesis strategy. Students used a double-stranded plasmid containing GFP-tagged YCK2 as template. The initial steps in site-directed mutagenesis were DNA denaturation and primer annealing, followed by primer extension. After repetition of these steps, E. coli produced (methylated) template DNA (shown in bold) was selectively digested with the methylation-specific restriction enzyme Dpn1 and the mutant plasmid was introduced into E. coli for nick repair and amplification. The figure is based on literature provided with the QuikChange kit (Stratagene).

each of which allowed the students to perform a complementation test to determine whether their mutant allele was functional. After performing the assays for function, students used microscopy to examine yeast expressing their mutant alleles to assess cellular morphology and Yck2 relative abundance and subcellular localization (via the GFP tag). A timeline for the project is given in Table 2. During most phases of the project, students were provided with explicit instructions to help them complete unfamiliar methods. As the students' familiarity with standard molecular biology techniques increased, however, they performed procedures such as analytical digests and bacterial and yeast transformations without specific guidance (Table 2).

\section{Experimental Results}

Students identified three amino acid sequences at least six residues long that were highly conserved in CK1s but not in other kinases (Figure 1). After examining the locations of these sequences within a three-dimensional representation of a CK1 from fission yeast, the students formed hypotheses about the function of each sequence. For example, one student group proposed that the conserved sequence LLGPSLED stabilizes ATP binding through interaction with the adenine ring, whereas another group hypothesized that the conserved sequence EQSRRDD assists in substrate binding. Each lab section then chose a single sequence on which to focus and devised a different mutation for each student group (Table 1). Each student group found and aligned the predicted amino acid sequence with the nucleotide sequence of YCK2 to allow them to design forward and reverse primers to introduce the desired mutation (Table 1). In selected cases, the primers that students ordered were supplemented with instructor-designed primers (Table 1). Using these primers and the QuikChange site-directed mutagenesis strategy, students successfully generated 15 mutations within the conserved sequences they had identified (Table 3). In some cases, the inclusion of the instructor-designed primers proved to be especially useful. For example, the students planning to delete the amino acids LLGPSLED designed primers that had only 11 and 12 nucleotides flanking the deletion site. The instructors ordered an additional primer set that included 14 and 15 nucleotides flanking the deletion site (Table 1). The students used both primer sets in site-directed mutagenesis reactions but were successful only with the instructor-designed primers. Thus, the inclusion of both primer pairs allowed the experiment to proceed as needed for progression of the project while also encouraging students to consider elements of successful primer design.

After confirming generation of the desired mutant alleles via sequence analysis of the relevant region of YCK2, students spent several lab sessions cloning the mutant allele into a yeast/E. coli shuttle vector marked with LEU2. After amplifying and purifying their new plasmids, they transformed two strains of yeast, $y c k^{t s}$ and $y c k \Delta$ yeast, to perform two independent assays of their mutant allele's function. In the $y c k^{t s}$ yeast, YCK1 has been deleted and the protein product of $y c k 2-2^{t s}$ functions at $24^{\circ} \mathrm{C}$ but has little activity at $37^{\circ} \mathrm{C}$ (Robinson et al., 1993), allowing the strain to grow at $24^{\circ} \mathrm{C}$ but not at $37^{\circ} \mathrm{C}$. Thus, expression of the mutant alleles in this strain allows the students to perform a complementation test by testing whether their mutant allele sustains growth at $37^{\circ} \mathrm{C}$. In the $y c k \Delta$ strain, both $Y C K 1$ and $Y C K 2$ have been deleted, and Yck activity is provided by a plasmid-borne YCK2 allele ( $p R S 316$ : YCK2; URA3). Thus, expression of the mutant alleles in this strain allows the students to perform a plasmid shuffle assay (Elledge and Davis, 1988) to determine whether their mutant gene product can sustain growth in the absence of any other Yck activity. This assay tests whether a resident plasmid that is required for viability can be replaced by an introduced plasmid, taking advantage of the ability to select against cells carrying an intact URA3 gene using 5-FOA. 5-FOA is converted to the toxic compound 5-fluorouracil in the presence of a functional URA3 gene. Because cells cannot grow on 5-FOA medium if they carry the URA3 plasmid, and they cannot grow in the absence of functional Yck, students were able to observe growth of the $y c k \Delta$ yeast on 5-FOA only if their mutant allele, present on the LEU2 plasmid, encodes a functional Yck2 protein. Growth rate and morphology of the strains on 5-FOA medium can provide indicators of the level of activity of the mutant protein, because each is compromised if activity is low.

For both strains of yeast, the students performed three transformation controls: one control in which cells were incubated only with carrier DNA, to demonstrate that no 
Table 2. Timeline of laboratory activities

\begin{tabular}{|c|c|c|}
\hline Wk & Activities & Explicit instructions provided to students? \\
\hline 1 & $\begin{array}{l}\text { Introduction to protein kinases } \\
\text { Identification of conserved amino acid sequences in CK1 protein kinase subfamily } \\
\text { Determination of mutations to make }\end{array}$ & Yes \\
\hline 2 & Mutagenic primer design and ordering & Yes \\
\hline 3 & Site-directed mutagenesis with Stratagene QuikChange kit & Yes \\
\hline 4 & $\begin{array}{l}\text { Isolation of mutated plasmid DNA } \\
\text { Analytical digest/gel electrophoresis } \\
\text { Prepare samples for sequencing }\end{array}$ & Yes \\
\hline 5 & $\begin{array}{l}\text { Analysis of sequencing results } \\
\text { Restriction digest to cleave mutated gene fragment and prepare E. coli/yeast } \\
\text { shuttle vector for ligation }\end{array}$ & Yes \\
\hline 6 & $\begin{array}{l}\text { Gel electrophoresis to isolate mutated gene fragment and digested shuttle vector } \\
\text { DNA purification }\end{array}$ & Yes \\
\hline 7 & $\begin{array}{l}\text { Ligation of mutated gene fragment into shuttle vector } \\
\text { Transformation of } E \text {. coli with ligation mix }\end{array}$ & $\begin{array}{l}\text { Yes } \\
\text { No }\end{array}$ \\
\hline 8 & $\begin{array}{l}\text { Isolation of plasmid DNA } \\
\text { Analytical digest/gel electrophoresis }\end{array}$ & No \\
\hline 9 & $\begin{array}{l}\text { Yeast transformation } \\
\text { Colonies patched to permissive conditions } \\
\text { Patches replica-plated to permissive and restrictive conditions }\end{array}$ & Yes \\
\hline 10 & $\begin{array}{l}\text { Analysis of growth results } \\
\text { Fluorescence microscopy }\end{array}$ & No \\
\hline
\end{tabular}

$\mathrm{Leu}^{+}$colony could arise in the absence of LEU2 plasmid; a positive control, in which cells were transformed with a plasmid carrying a wild-type GFP-tagged YCK2 gene; and a negative control, in which cells were transformed with the empty LEU2 vector. In each case, the transformed cells were initially grown under conditions that selected for the transforming plasmid (-Leu medium) but were otherwise per- missive (i.e., $y c k^{t s}$ yeast were grown at $24^{\circ} \mathrm{C}$; $y c k \Delta$ yeast were grown in the absence of 5-FOA). After the development of colonies, colonies were patched to fresh media and allowed to develop under the same conditions. Patches were then replica-plated to media incubated in both permissive and restrictive conditions, allowing students to determine the function of their mutant alleles. Representative student re-

Table 3. Results from student-designed mutations

\begin{tabular}{|c|c|c|c|c|c|c|}
\hline Conserved sequence & Mutation & $\begin{array}{l}\text { Introduction of } \\
\text { mutation } \\
\text { successful? }\end{array}$ & $\begin{array}{l}\text { Effect on } \\
\text { cell } \\
\text { division? }\end{array}$ & $\begin{array}{c}\text { Effect on } \\
\text { morphology? }\end{array}$ & $\begin{array}{c}\text { Effect on } \\
\text { localization? }\end{array}$ & $\begin{array}{l}\text { Relative protein abundance } \\
\text { (\% of wild type; inferred } \\
\text { from GFP signal) }\end{array}$ \\
\hline \multirow[t]{5}{*}{${ }^{151}$ LLGPSLED } & $\Delta$ LLGPSLED & Yes & Yes & Yes & $\begin{array}{l}\text { Yes-increased on } \\
\text { internal } \\
\text { membranes }\end{array}$ & 100 \\
\hline & $\Delta \mathrm{LLG}$ & Yes & Yes & Yes & No & 100 \\
\hline & $\begin{array}{l}\Delta \mathrm{P} \\
\Delta \mathrm{PSLED}\end{array}$ & $\begin{array}{l}\text { Yes } \\
\text { No }\end{array}$ & Yes & Yes & No & 100 \\
\hline & $\mathrm{P} \rightarrow \mathrm{W}$ & Yes & No & No & No & 100 \\
\hline & $\mathrm{P} \rightarrow \mathrm{E}$ & Yes & No & No & $\mathrm{N} / \mathrm{A}$ & Not detected \\
\hline \multirow[t]{6}{*}{${ }^{233} \mathrm{HIPYRE}$} & $\Delta \mathrm{P}$ & Yes & Yes & Yes & No & 100 \\
\hline & $\mathrm{P} \rightarrow \mathrm{V}$ & Yes & No & No & No & 100 \\
\hline & $\mathrm{P} \rightarrow \mathrm{T}$ & Yes & No & No & No & 100 \\
\hline & $\Delta \mathrm{Y}$ & Yes & Yes & Yes & No & 100 \\
\hline & $\mathrm{Y} \rightarrow \mathrm{F}$ & Yes & No & No & No & 100 \\
\hline & $\mathrm{Y} \rightarrow \mathrm{S}$ & Yes & Yes & No & No & 100 \\
\hline \multirow[t]{6}{*}{${ }^{258}$ EQSRRDD } & $\Delta \mathrm{EQS}$ & Yes & Yes & Yes & $\begin{array}{l}\text { Yes-dispersed } \\
\text { and punctuate } \\
\text { cytosolic }\end{array}$ & $<50$ \\
\hline & $\Delta \mathrm{S}$ & Yes & Yes & Yes & No & 100 \\
\hline & $\mathrm{S} \rightarrow \mathrm{T}$ & Yes & No & Yes & No & 100 \\
\hline & $\mathrm{S} \rightarrow \mathrm{C}$ & No & & & & \\
\hline & $\mathrm{DD} \rightarrow \mathrm{NN}$ & Yes & Yes & Yes & No & $<100$ \\
\hline & RRDD $\rightarrow$ GGGG & No & & & & \\
\hline
\end{tabular}


sults are shown in Figure 3A. A summary of the outcomes of all the student mutations is shown in Table 3.

After performing these two assays to determine whether their mutant alleles were functional, students examined yeast cells expressing their mutant alleles microscopically to assess morphology and Yck2 relative abundance and subcellular localization (via the GFP tag). A summary of results is shown in Table 3, and representative student results are shown in Figure 3B. Most mutant proteins were expressed at comparable levels to the wild-type protein. Two notable exceptions are indicated. Note that in Table 3, 100\% represents a range of fluorescence intensities similar to that seen for wild-type cells, $<100 \%$ is lower than wild-type cells but not $<50 \%$, and $<50 \%$ indicates up to 10 -fold reduction in fluorescence. Note also that few mutant proteins showed

A
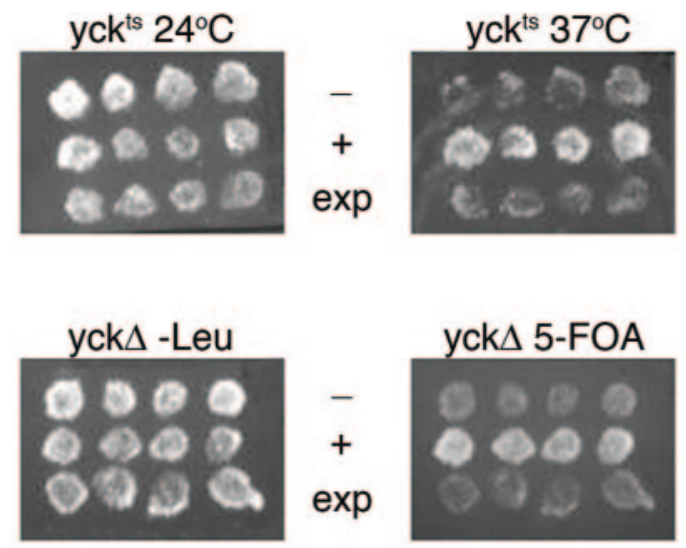

B
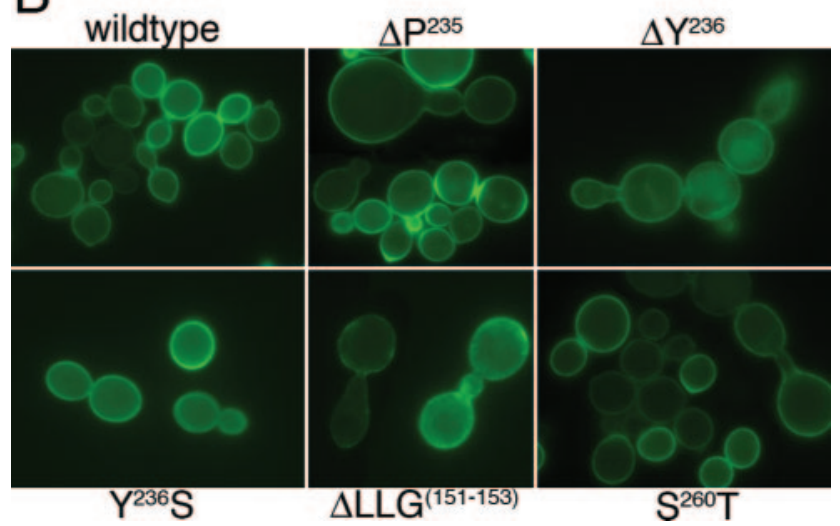

Figure 3. Representative student results. (A) Deletion of Pro from the highly conserved LLGPSLED sequence abolishes Yck2 function. Top, results from $y c k^{t s}$ yeast (top) and $y c k \Delta$ yeast (bottom) transformed with empty vector (top rows on plates), vector containing wild-type $Y C K 2$ (middle rows on plates), and the mutant YCK2 allele (bottom rows on plates) and grown overnight in permissive (left) and restrictive (right) conditions. (B) Fluorescence images of representative $y c k \Delta$ cells transformed with vector containing the mutant YCK2 allele and incubated overnight in restrictive conditions are shown. Cells expressing wild-type GFP-Yck2 and five different mutant GFP fusions, at least one from each conserved sequence, are shown. All five mutants showed at least as much fluorescence on average as cells expressing wild-type GFP-Yck2, but many display abnormal morphology. alteration in localization. We show cells expressing wildtype GFP-Yck2 and five different GFP-Yck2 variants in Figure $3 \mathrm{~B}$. The five variants are representative of the majority we examined.

\section{Student Learning Outcomes}

Student learning was assessed with a knowledge survey at the beginning of the course and after completion of the course. Specifically, this survey was designed to determine whether students gained an understanding of the genetics concepts and molecular biology techniques used within the project. We also included questions to determine whether students had gained the ability to use the bioinformatics tools used during the project. A comparison of the pre- and posttest results displays significant learning gains for all tested areas except one area. Students displayed a significant increase in their understanding of all the molecular techniques used except for DNA sequencing (Figure 4A); the students' ability to answer this question was very high on the pretest, probably due to basic understanding of DNA structure. Students also showed a significant increase in the ability to interpret and predict results from techniques used in the project (Figure 4B), and they showed a significant increase in their ability to use several of the bioinformatics tools used during the project (Figure 4C). In addition to comparing pre- and posttest results for individual questions, we also compared composite pre- and posttest scores for individual students (Figure 4D). This analysis also revealed significant increases in student knowledge, with every student increasing his or her score from the pretest to the posttest.

Students presented their results in two lab reports during the course of the semester, the first of which they were encouraged to revise based on instructor comments and suggestions. The first lab report detailed the identification of conserved sequences within CK1 enzymes, their location within the proteins' three-dimensional structure, the rationale for their mutation, and the results from the site-directed mutagenesis. The reports were assessed using the rubric supplied as Supplemental Material 2, which was provided to students when they received the assignment. In addition, instructors provided extensive commentary to aid revision, and, hopefully, to develop an improved understanding of effective scientific communication. Students were encouraged to revise the report, and all but one student did so. The second lab report described cloning the mutant alleles into the shuttle vector as well as the functionality assays and the microscopy observations. This report was assessed using a rubric that was very similar to the rubric used for the first report but that was adjusted to reflect the added importance of discussing the overall implications of the students' results. A comparison of the lab report assessments revealed that the revision process resulted in a significant improvement in the quality of lab report 1 and that this improvement was maintained in lab report 2 (which was not subject to revision; Figure 5). A comparison of normalized scores for the various sections of the lab reports (e.g., Introduction, Materials and Methods, and so on) indicated significant ( $p<$ 0.05 ) improvements in every section of the lab report, both when comparing lab report 1 with the revised version and when comparing lab report 1 with lab report 2 . When com- 
A

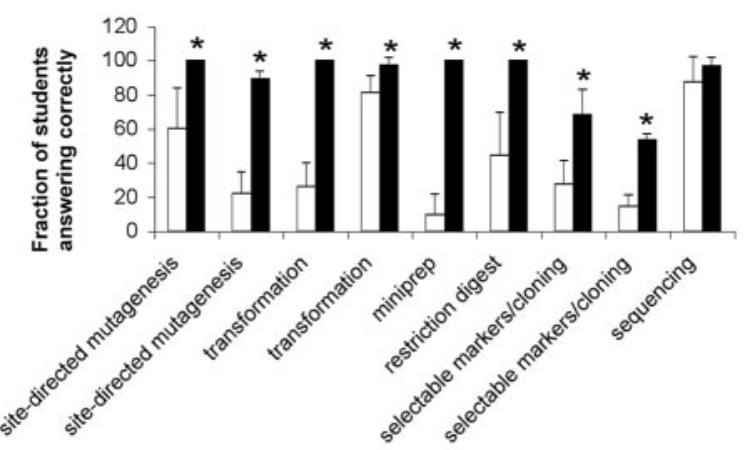

B
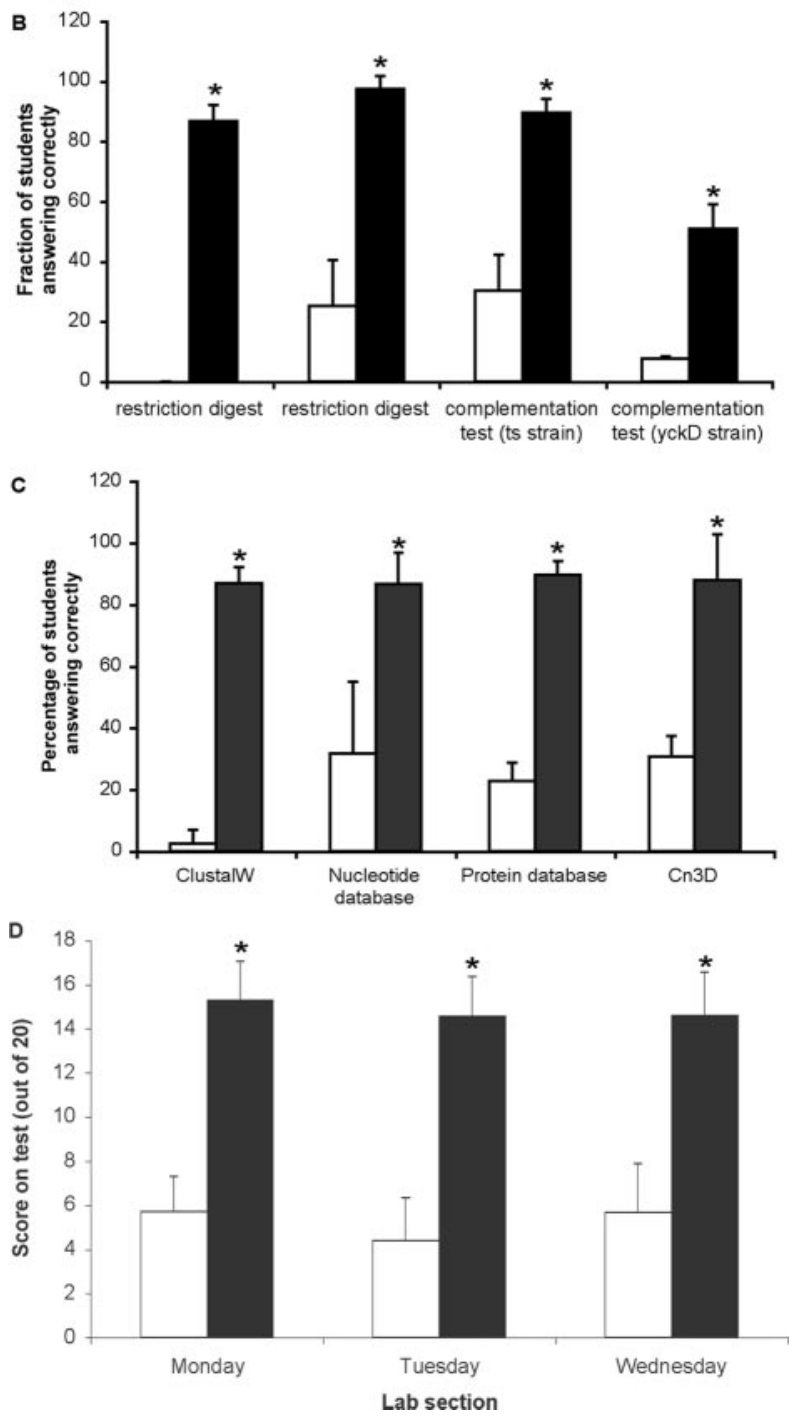

Figure 4. Student learning gains. Student performance on a knowledge survey delivered at the beginning of the course and after completion of the course is compared. We compared student responses to questions assessing knowledge and understanding of common molecular biology techniques $(\mathrm{A})$, ability to interpret and predict results from common techniques (B), and ability to use bioinformatics tools (C). (D) Comparison of composite student performances on pre- and posttests. A one-tailed, paired Student's $t$ test was used for all comparisons. White bars, pretest results; black bars, posttest results. ${ }^{*} p<0.05$.

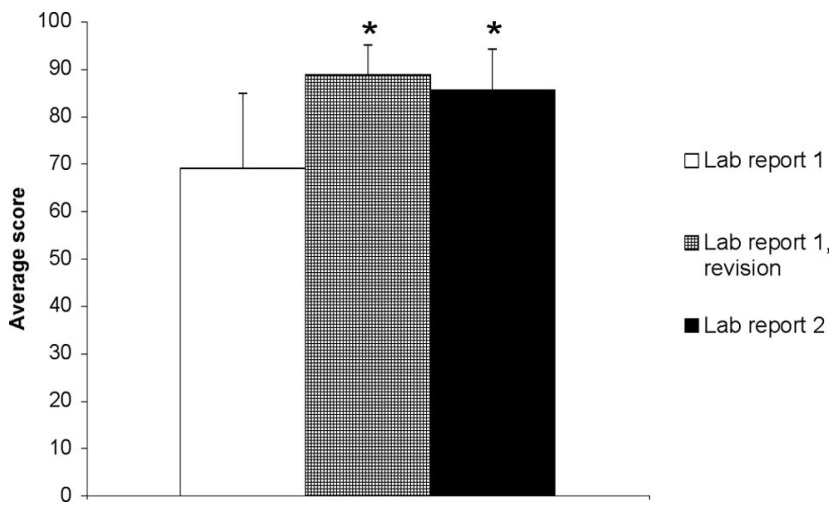

Figure 5. Student performance on lab reports. Student lab reports were assessed using rubrics provided to the students during report preparation (see Supplemental Material 2). Scores from the revision of lab report 1 and lab report 2 were normalized to 100 points and compared with scores from lab report 1 by using a two-tailed, paired Student's $t$ test. ${ }^{*} p<0.05$

paring student performance on the revised version of lab report 1 with lab report 2 , we observed a slight but significant $(p<0.01)$ improvement in the Materials and Methods section and a slight but significant $(p=0.02)$ decline in the Discussion section, perhaps due to students' relative lack of familiarity with the more extensive discussion required for a completed project.

Student perception of the project was positive (Table 4). Students agreed that the project improved their knowledge of techniques essential for molecular biology experiments "somewhat" (11\%), "quite a bit" (19\%) or "very much" $(70 \%)$ as well as their ability to interpret data from molecular genetics techniques $(13.5,30$, and $54 \%)$. They also agreed

Table 4. Student assessment of molecular biology lab experiment

\section{Question}

Mean

response $\pm \mathrm{SD}$

1. Do you feel that the semester-long genetics project you completed last year

a. Increased your understanding of the multi- $\quad 4.59 \pm 0.76$ step process necessary in many experiments?

b. Increased your knowledge of techniques $\quad 4.59 \pm 0.69$ essential for molecular genetics experiments?

c. Improved your ability to interpret data from molecular genetics techniques?

d. Improved your ability to write lab reports? $4.25 \pm 0.69$

2. Do you feel that the revision process allowed $\quad 4.68 \pm 0.53$

you to improve your scientific writing skills?

3. Overall, was the lab project a useful experience?

$4.62 \pm 0.64$

Mean responses \pm SD are shown. Questions from evaluations are listed. Instructions on the surveys read, "Please enter your choice for each question in the cell adjacent to the question. 1, Not at all, 2, Very little, 3, Somewhat, 4, Quite a bit; and 5, Very much." 
"somewhat" (14\%), "quite a bit" (47\%), or "very much" $(38 \%)$ that the project improved their ability to write lab reports, and thought that the revision process helped in this improvement $(3,27$, and $70 \%)$.

\section{DISCUSSION}

This article describes a laboratory project for an intermediate-level genetics course enrolled with a broad variety of students. During the course of the project, students use a variety of bioinformatics tools to frame a question and design an experiment. They then gain experience with a variety of current laboratory techniques in performing their experiment and with scientific writing while reporting their work. Thus, the project allows students to pursue original research as part of a required course. It also emphasizes the benefits of cooperativity in research; while designing their experiments, students quickly realized that their understanding of a particular conserved sequence would be greater if various groups performed complementary mutations within the sequence.

Assessment of student learning indicated that students completing the course showed significant gains in their understanding of the genetics concepts and molecular biology techniques used during the project. They also demonstrated significant gains in their ability to use the bioinformatics tools used in their research and showed an increased ability to communicate the results of their research in the form of a lab report. In assessing the course, we noted several changes we would like to make. Although the pre- and posttest the students completed indicated a significant increase in knowledge in almost all categories, discussions with students completing the course have suggested that it would be helpful to offer the option "I don't know" or "I have no idea" in the future. Not only would this serve to reduce false positives on the pretest (Hood-DeGrenier, 2008), but several students indicated that they would have been more comfortable providing this more honest answer on the pretest. In addition, we would like to include more opportunities for improving scientific presentation skills in the future. To aid in this goal, we plan to add a weekly homework assignment in which students complete a figure, figure legend, and accompanying text for work they completed in lab that week. Not only would this practice allow students to receive feedback on their writing each week but also it would help students construct parts of their lab reports as they progress through the project. Because many students found the lab reports daunting, we feel this progressive construction of materials for the lab report would be helpful. Although the students were somewhat intimidated by the lab reports, the increased scores between lab report 1 and lab report 2 indicate progress not only in learning concepts and techniques but also in ability to understand and interpret results. The difference in weight given to the discussion between lab reports 1 and 2 makes more significant the increased scores, because the discussion was worth a greater fraction of the total points ( $\sim 16 \mathrm{vs} .30 \%)$ in lab report 2 .

The course enrolls approximately $40-50$ students of varied backgrounds every spring. The students enrolled are approximately equally distributed among their sophomore, junior, and senior years, and they are typically biology, biochemistry, biophysics, chemistry, or neuroscience majors. There is one faculty instructor for each section of 15-18 students. The course meets for $3 \mathrm{~h} / \mathrm{wk}$ for $14 \mathrm{wk}, 10$ of which are devoted to the project; students are also occasionally required to come in outside of scheduled lab time to complete small tasks to keep the project progressing. With the exception of the two yeast strains described above and the template DNA used in the mutagenesis reaction, all of the tools used in the project are commercially available or freely available on the World Wide Web. The template plasmid used in site-directed mutagenesis and both yeast strains are available upon request from the authors. As described here, the cost of the project is approximately $\$ 100 /$ student; the cost could be reduced by decreasing the use of kits, decreasing the number of primers ordered, or decreasing the number of sequencing reactions. It is important to note that all bioinformatics tools used are freely available on the World Wide Web and that all are student-friendly and easy to use.

The project can be modified easily to allow students to investigate any gene for which there is a relatively simple functionality assay. It also can be modified to be a shorter project if site-directed mutagenesis is performed on template DNA that allows direct expression in the model organism, allowing the cloning steps performed in this project to be eliminated. These modifications would be most effectively accomplished in collaboration with an active yeast research lab, but they also could build from collections of yeast deletion strains (Saccharomyces Genome Deletion Project; sequence-www.stanford.edu/group/yeast_deletion_project/ deletions3) and overlapping plasmids that cover the yeast genome (steelhead.aecom.yu.edu/SystematicLibrary; www. openbiosystems.com/GeneExpression/Yeast/GenomicTiling).

Finally, the project has proved to be a sound starting point for independent student research projects. Three productive student research projects developed from the initial semester in which this project was implemented. The three students integrated the mutant alleles into the yeast chromosome to better assess the ability of each mutant protein to fulfill requirement for Yck1,2 activity. Students also transferred their mutant alleles into vectors for fusion protein production and isolated and purified fusion protein for in vitro protein kinase assays. These ongoing projects have produced interesting results that the students have presented at a Centenary College research forum. In addition, they will lead to two student presentations at regional or national meetings and likely will be included in one or more research publications.

In summary, the project described here adds to the growing repertoire of inquiry-based projects students may complete in a laboratory course (e.g., Gammie and Erdeniz, 2004; Goyette and DeLuca, 2007). Students use a variety of bioinformatics tools to frame a question and then use common molecular biology techniques to perform their experiment. The project is appropriate for students with a variety of backgrounds, and is flexible enough to allow modification for labs with different time and budget constraints. Finally, the original research aspect of the project adds motivation to complete each step, and it is likely to generate results that can serve as the basis for individual student projects in the instructor's lab, or even to serve as preliminary data for a larger project involving more students. The positive student 
response to the project indicates that the approach was effective for both motivation and learning.

\section{ACKNOWLEDGMENTS}

We thank Spencer Saulsbury for help in preparing figures; Emily Davis and Jessica Miller for example hypotheses; and Allison Cormier, Danielle Crouthers, Danielle Dupree, Derek Fogleman, and Spencer Saulsbury for use of data. This work was supported by a Centenary College Research Professorship in the Natural Sciences (to C.J.B.) and National Science Foundation grant MCB-0517204 (to L.C.R. and C.J.B.).

\section{REFERENCES}

Altschul, S. F., Gish, W., Miller, W., Myers, E. W., and Lipman, D. J. (1990). Basic local alignment search tool. J. Mol. Biol. 215, 403-410.

Babu, P., Deschenes, R. J., and Robinson, L. C. (2004). Akr1p-dependent palmitoylation of Yck2p yeast casein kinase I is necessary and sufficient for plasma membrane targeting. J. Biol. Chem. 279, 2713827147.

Brockman, J. L., Gross, S. D., Sussman, M. R., and Anderson, R. A. (1992). Cell cycle-dependent localization of casein kinase I to mitotic spindles. Proc. Natl. Acad. Sci. USA 89, 9454-9458.

Council on Undergraduate Research (1997). Shaping the Future: New Expectations for Undergraduate Education in Science, Mathematics, Engineering, and Technology, Washington, DC. www. cur.org/shaping (accessed 11 March 2007).

Eberhardt, E. S., Hansen, J., Riservato, L., Cole, M. Smaglo, B., and Szaniawski, P. (2003). Preparing undergraduates to participate in the post-genome era. Biochem. Mol. Biol. Educ. 31, 402-409.

Elledge, S. J., and Davis, R. W. (1988). A family of versatile centromeric vectors designed for use in the sectoring-shuffle mutagenesis assay in Saccharomyces cerevisiae. Gene 70, 303-312.

Faundez, V. V., and Kelly, R. B. (2000). The AP-3 complex required for endosomal synaptic vesicle biogenesis is associated with a casein kinase I alpha-like isoform. Mol. Biol. Cell 11, 2591-2604.

Flotow, H., and Roach, P. J. (1989). Synergistic phosphorylation of rabbit muscle glycogen synthase by cyclic AMP-dependent protein kinase and casein kinase I: implications for hormonal regulation of glycogen synthase. J. Biol. Chem. 264, 9126-9128.

Gammie, A. E., and Erdeniz, N. (2004). Characterization of pathogenic human MSH2 missense mutations using yeast as a model system: a laboratory course in molecular biology. Cell Biol. Educ. 3, 31-48.

Gietz, R. D., and Schiestl, R. H. (1991). Applications of high efficiency lithium acetate transformation of intact yeast cells using single-stranded nucleic acids as carrier. Yeast 7, 253-263.

Goyette, S. R., and DeLuca, J. (2007). A semester-long studentdirected research project involving enzyme immunoassay: appropriate for immunology, endocrinology, or neuroscience courses. CBE Life Sci. Educ. 6, 332-342.

Hanks, S. K. (2003). Genomic analysis of the eukaryotic protein kinase superfamily: a perspective. Genome Biol. 4, 111-117.

Hanks, S. K., and Hunter, T. (1995). The eukaryotic protein kinase superfamily: kinase (catalytic) domain structure and classification. FASEB J. 9, 576-596.

Hanks, S. K., Quinn, A. M., and Hunter, T. (1988). The protein kinase family: conserved features and deduced phylogeny of the catalytic domains. Science $241,42-52$.
Higgins, D. G., and Sharp, P. M. (1988). CLUSTAL: a package for performing multiple sequence alignment on a microcomputer. Gene $73,237-244$

Hood-DeGrenier, J. K. (2008). A Western blot-based investigation of the yeast secretory pathway designed for an intermediate-level undergraduate cell biology laboratory. CBE Life Sci. Educ. 7, 107-117.

Howard, D. R., and Miskowski, J. A. (2005). Using a module-based laboratory to incorporate inquiry into a large cell biology course. Cell Biol. Educ. 4, 249-260.

Howard Hughes Medical Institute (1996). Beyond Bio 101, The Transformation of Undergraduate Biology Education, Chevy Chase, MD: Howard Hughes Medical Institute. http://www.hhmi.org/ BeyondBio101 (accessed 11 March 2007).

Lee, C., Etchegaray, J., P., Cagampang, F. R., Loudon, A. S., and Reppert, S. M. (2001). Posttranslational mechanisms regulate the mammalian circadian clock. Cell 107, 855-867.

Knippschild, U., Milne, D. M., Campbell, L. E., DeMaggio, A. J., Christenson, E., Hockstra, M. F., and Meek, D. W. (1997). p53 is phosphorylated in vitro and in vivo by the delta and epsilon isoforms of casein kinase 1 and enhances the level of casein kinase 1 delta in response to topoisomerase-directed drugs. Oncogene 15, 1727-1736.

Marchal, C., Dupré, S, and Urban-Grimal, D. (2002). Casein kinase I controls a late step in the endocytic trafficking of yeast uracil permease. J. Cell Sci. 115, 217-226.

Mitchell, B. F., and Graziano, M. R. (2006). From organelle to protein gel: a 6-wk laboratory project on flagellar proteins. CBE Life Sci. Educ. 5, 239-246.

Myers, M. J., and Burgess, A. B. (2003). Inquiry-based laboratory course improves students' ability to design experiments and interpret data. Adv. Physiol. Educ. 27, 26-33.

National Research Council (2003). Biology 2010, Transforming Undergraduate Education for Future Research Biologists, Washington, DC: National Academies Press.

Panek, H. R., Stepp, J. D., Engle H. M., Marks, K. M., Tan, P. K., Lemmon, S. K., and Robinson, L. C. (1997). Suppressors of YCKencoded yeast casein Kinase 1 deficiency define the four subunits of a novel clathrin AP-like complex. EMBO J. 16, 4194-4204.

Robinson, L. C., Menold, M. M., Garrett, S., and Culbertson, M. R. (1993). Casein kinase I-like protein kinases encoded by YCK1 and YCK2 are required for yeast morphogenesis. Mol. Cell. Biol. 13, 2870-2881.

Robinson, L. C., Bradley, C., Bryan, J. D., Jerome, A., Kweon, Y., and Panek, H. R. (1999). The Yck2 yeast casein kinase 1 isoform shows cell cycle-specific localization to sites of polarized growth and is required for proper septin organization. Mol. Biol. Cell 10, 10771092.

Roth, A. F., Feng, Y., Chen, L., and Davis, N. G. (2002). The yeast DHHC cysteine-rich domain protein Akr1p is a palmityl transferase. J. Cell Biol. 159, 23-28.

Rubinfeld, B., Tice, D. A., and Polakis, P. (2001). Axin-dependent phosphorylation of the adenomatous polyposis coli protein mediated by casein kinase 1 epsilon. J. Biol. Chem. 276, 39037-39045.

Sambrook, J., Fritsch, E. F., and Maniatis, T. (1989). Molecular Cloning: A Laboratory Manual, Plainview, NY: Cold Spring Harbor Press.

Schwab, C., DeMaggio, A. J., Ghoshal, N. Binder, L. I., Kuret, J., and McGeer, P. L. (2000). Casein kinase 1 delta is associated with pathological accumulation of tau in several neurodegenerative diseases. Neurobiol. Aging 21, 503-510.

Sherman, F., Fink, G. R., and Hinks, J. B. (1986). Methods in Yeast Genetics, Cold Spring Harbor, NY: Cold Spring Harbor Laboratory. 
Sikorski, R. A., and Hieter, P. (1989). A system of shuttle vectors and yeast host strains designed for efficient manipulation of DNA in Saccharomyces cerevisiae. Genetics 122, 19-27.

Stukus, P., and Lennox, J. E. (2001). Use of an investigative semester-length laboratory project in an introductory microbiology course. In: Practicing Science, Arlington, VA: National Science Teachers Association.

Tobin, A. B., Totty, N. F., Sterlin, A. E., and Nahorski, S. R. (1997). Stimulus-dependent phosphorylation of G-protein-coupled receptors by casein kinase 1 alpha. J. Biol. Chem. 272, 20844-20849.
Tuazon, P. T., and Traugh, J. A. (1991). Casein kinase I and IImultipotential serine kinases: structure, function, and regulation. Adv. Second Messenger Phosphoprotein Res. 23, 129-164.

Vancura, A., Sessler, A., Leichus, B., and Kuret, J. (1993). Isolation and properties of YCK2, a Saccharomyces cerevisiae homolog of casein kinase-1. Arch. Biochem. Biophys. 305, 47-53.

Vielhaber, E., Eide, E., Rivers, A., Gao, Z. H., and Virship, D. A. (2000). Nuclear entry of the circadian regulator mPER1 is controlled by mammalian casein kinase I epsilon. Mol. Cell. Biol. 20, 48884899. 